\title{
El movimiento social de los migrantes «sin papeles» en Cataluña. Apuntes para una aproximación sociológica
}

\author{
Amarela Varela Huerta \\ Universitat Autònoma de Barcelona. Departament de Sociologia \\ Grup d'Estudis d'Immigració i Minories Ètniques (GEDIME) \\ 08193 Bellaterra (Barcelona). Spain
}

\section{Resumen}

Esta nota de investigación se centra en el movimiento social protagonizado por migrantes "con y sin papeles» en Cataluña. En ella expongo la perspectiva general, teórica y metodológica que utilizo para mi trabajo de investigación doctoral.

Propongo una perspectiva en la que el migrante «con y sin papeles» y su acción colectiva sean considerados como un nuevo tipo de actor social con agencia política. Asimismo, sugiero entender este movimiento como una identidad política híbrida y transnacional.

Finalmente, propongo que el marco analítico para el abordaje de tal fenómeno social se base en los instrumentos de la escuela cualitativa de la sociología.

Palabras clave: movimiento social de migrantes «con y sin papeles», agencia política, ciudadanía, prácticas políticas híbridas y transnacionales, mirada cualitativa en sociología.

Abstract. The «sin papeles» migrant social movement in Catalonia. A sociological approach

This note is focus in the con y sin papeles migrant social movements in Catalonia. On this note I expose the general perspective, theoretic and methodological, which I use for my doctoral research work. I propose a perspective in which the con y sin papeles migrant, and his collective action, can be considered like a new kind of social actor, with political agency. Likewise, I suggest understanding this social movement like a political hybrid and transnational identity.

Finally, I propose to work with an analytical frame about this social movement based on the instruments of the qualitative perspective of sociology.

Key words: "con y sin papeles» migrant social movement, policital agency, citizenship, hibrid and transnational political practices, sociological cualitative perspective.

Hoy en día, en la sociedad española en general, y muy acentuadamente en Cataluña, acontece un acelerado proceso de reconfiguración social como consecuencia de la cada vez mayor pluralidad sociocultural e identitaria de su población.

En este proceso de redefinición de los espacios públicos y privados y de las relaciones sociales, intervienen diversos protagonistas, entre los que cabría destacar los poderes públicos en todos sus niveles, los medios de comunicación, las 
instituciones educativas, los técnicos y expertos en el fenómeno migratorio, la denominada «sociedad civil»y, en ella, especialmente, los propios sujetos migrantes.

Llegados de otros países de la Unión Europea, pero mayoritariamente de todas las periferias, 3.730.630 extranjeros (entre los que se cuentan los migrantes «sin papeles», los migrantes regularizados y los extranjeros eurocomunitarios) conviven hoy con 40.377.920 de «españoles», por lo cual es, pues, "no nacional» el 8,5\% de la población total que habita en el Estado español ${ }^{1}$.

Por los registros de los que disponemos, sabemos que de entre los 3.730.630 habitantes que no poseen la nacionalidad española, 990.698 personas se encuentran sin reconocimiento de su estatus jurídico fundamental ${ }^{2}$. Es decir, en el Estado español aproximadamente un millón de personas carecen de subjetividad ante la ley y las instituciones.

Víctimas del capitalismo global, refugiados económicos o políticos, estos «sin papeles» son también personas que, por haberse desplazado, pierden, en el trayecto, el derecho al ejercicio de la ciudadanía, y lo que es más grave, pierden el reconocimiento como sujetos jurídicos y, con ello, el acceso a los derechos fundamentales.

Antaño, al inicio de lo que se ha venido a llamar el «boom inmigratorio español», las formas de visibilización de estos sujetos sin reconocimiento jurídico se paterizó, se criminalizó, se victimizó y, por ello, hoy las figuras que los nombran en el espacio público y mediático español y catalán son las que se asocian con pateras, centros de internamiento y de estancia temporal, detenciones, trabajo «en negro", prostitución, delincuencia, tráfico de personas, muerte, clandestinidad, persecución, fuga (GRIM: 2005). En suma, la migración es tratada como un grave problema social de dimensiones europeas, que suele vincularse habitualmente al narcotráfico y al terrorismo internacional y que, además, tendría como consecuencia directa el dificultar la integración social de los migrantes regulares (Santamaría, 2002).

Aunque, paralelamente, y siempre anteponiendo su situación jurídica, la prensa y la sociedad españolas participaron en la construcción de una nueva categoría social que fue resignificada, lo que dio lugar a un nuevo sujeto y a una nueva identidad colectiva: los migrantes «sin papeles» organizados, quienes, ajenos a estructuras sindicales y partidistas, aparecieron en el espacio público español mediante una ola de encierros en iglesias, al estilo de las luchas sociales realizadas durante el franquismo, demandando «Papeles para todos».

Así pues, desde enero de 2001 y, cíclicamente, hasta este 2006, los «sin papeles» organizados toman iglesias, organizan huelgas de hambre, se mani-

1. Los datos son del Censo Nacional de Población 2005. Nota de prensa Explotación Estadística del Padrón municipal a 1 de enero de 2005 del 17.01.06 del Instituto Nacional de Estadística (INE).

2. La cifra de «sin papeles» propuesta se obtuvo cruzando los datos del INE del 17 de enero de 2005 (nota de prensa) con el del Informe Estadístico de la Secretaría de Estado en Inmigración y Emigración. MTAS (31 de diciembre de 2005). 
fiestan por las calles, demandan «regularización sin condiciones» y ser reconocidos como «interlocutores» ante las administraciones autonómica y estatal.

Así, siguiendo el ejemplo del movimiento de la Coordinadora Nacional de «sin papeles» en Francia (Cissé, 2000), los «sin papeles» se organizan en diferentes grupos y espacios políticos para demandar, también con estrategias diferentes y algunas veces contrapuestas, su reconocimiento como sujetos de derecho.

En Barcelona, ejemplos como el del 5 de junio de 2004, cuando unos mil quinientos migrantes «sin papeles» ocupaban la catedral de la capital catalana en demanda de la "Regularización sin Condiciones», reposicionó a ese actor político colectivo (aparecido por primera vez en los encierros del 2001) y el debate sobre lo que representan sus prácticas políticas híbridas, que resultan a su vez de la suma de trayectorias vitales de los migrantes.

Un nuevo actor, pues, los migrantes «sin papeles», que provocaba asimismo un giro semántico, categorial, en las narraciones periodísticas sobre el tema de la «inmigración ilegal en España», que, por sus acciones, demandaba ser reconocido, además de como víctima, como sujeto activo con prácticas políticas propias.

Y he ahí la génesis de los intereses investigativos de la tesis doctoral que preparo, que parte de la noción de que, con estrategias de visibilización y presión política como los encierros en iglesias, las huelgas de hambre o las manifestaciones reiteradas por las calles de ciudades catalanas, los «sin papeles», que carecen, según la normativa de extranjería vigente en España, del derecho a la libre asociación, a la reunión y a la participación, ponen en jaque las formas de nombrar la migración y cuestionan de raíz la política eurocomunitaria en materia de extranjería.

Unos intereses investigativos, por otro lado, que suscriben los desafíos que autores como Santamaría (2002), Mezzadra (2004) y García Canclini (2002) proponen a los estudiosos de la migración: hay que preguntarse por la subjetividad política y social del inmigrante. Hay que indagar el proceso de construcción sociopolítica y cognitiva de alteridades recién instaladas en espacios públicos previamente diversos.

Nuevo tipo de actor político y social en el espacio público catalán y español sobre el que hay que interrogarse: ¿Qué y quiénes son estos "sin papeles» que se manifiestan por las calles del centro de Barcelona? ¿Qué demandan? ¿Cómo se organizan? ¿Tienen estrategias para visibilizarse o actúan como reflejo a las tensiones que impone en su vida cotidiana la política de extranjería española que es a su vez eurocomunitaria? ¿De dónde vienen estos nuevos actores sociales y políticos? ¿Tienen experiencias previas de organización en los países que dejaron? ¿Qué actores del tejido social del país de acogida, en este caso Cataluña, les apoyan activa o coyunturalmente?.

Finalmente, es necesario acotar que la investigación que se propone suscribe, como campo de acción epistemológico, la línea de investigaciones sobre los movimientos sociales (Iñiguez, 2003; Laraña, 1999; Melucci, 1991, 1994), porque los interrogantes que le sirven de eje nodal se refieren (independien- 
temente de la pertenencia étnica o de la situación jurídica de sus miembros) a actores políticos colectivos en formación y consolidación.

Porque la intuición central de la que partimos es que estamos ante una identidad política hibridada y transnacionalizada, construida en base a diferentes tiempos y espacios políticos y que viene a confluir para demandar su reconocimiento en el espacio público catalán, en tanto sujeto social, jurídico, cultural y político.

\section{Investigación-acción: bitácora y herramientas para el trabajo de investigación}

Abordar el estudio de un movimiento social tan heterogéneo como el de los «sin papeles» en Barcelona (en el que participan, sobre todo, marroquíes, pakistaníes, bengalíes, indios, senegaleses y subsaharianos, y, de forma coyuntural y efímera, migrantes latinoamericanos) plantea el desafío metodológico de ser capaces de reconocer y, sobre todo, interpretar con complejidad analítica, las prácticas políticas cotidianas de sus miembros.

Y es por ello que me aproximo a este movimiento de migrantes «sin papeles» desde una perspectiva cualitativa, que usa como bitácora a la escuela metodológica de la investigación-acción, o investigación social participativa (Villasante y otros, 2000).

Finalmente, para conseguir una mayor densidad interpretativa, elegí partir del estudio de un caso concreto de fenómeno social que me interesa describir sociológicamente ${ }^{3}$.

Así, la investigación doctoral que realizo se basa en recuperar la memoria colectiva del accionar político de los miembros de una de las dos principales asociaciones de "sin papeles» autoorganizados en Cataluña: Asociación por la libre Circulación de las Personas Cornellà sin Fronteras (ACSF).

Fundada en noviembre de 2001 por activistas catalanes y, sobre todo, compuesta por miembros de la comunidad amazigh (mal llamado «pueblo bereber») ${ }^{4}$, que, con o sin "papeles», viven y trabajan en Cornellà, la ACSF sostiene desde su nacimiento movilizaciones en demanda de papeles y derechos para todos, proponiendo una serie de medidas que desvinculen el reconocimiento jurídico de personas migrantes de la lógica laboralista de la política migratoria española.

El trabajo de campo consiste en realizar entrevistas en profundidad (Alonso, 1998), sobre todo, con los migrantes con y sin «papeles» que han participado

3. Siguiendo a E. Stake, diremos que «El estudio de caso es el estudio de la particularidad y de la complejidad de un caso singular, para llegar a comprender su actividad en circunstancias importantes» (1998: 11). Entendiendo a todo estudio de caso como algo específico, pero, al mismo tiempo, complejo, en funcionamiento, como un sistema integrado.

4. La amplia mayoría de los integrantes de Cornellà sin Fronteras provienen de Er Rachidia, tal y como ellos definen «[...] una región de Marruecos, ubicada en un oasis de las laderas meridionales de las montañas del Atlas Mayor, 240 kilómetros al sureste de Meknes, en el valle del Ziz. Su población, de 45.710 habitantes, es, en su mayoría, de origen amazigh o berebern. 
en las movilizaciones de este movimiento desde el año 2000 y hasta la fecha. Entrevistas basadas en recuperar su biografía política, pero, sobre todo, en recuperar los argumentos que, sobre sus demandas, estrategias, estructuras de organización y alianzas con otros grupos, hagan los entrevistados.

Además, y para explorar las identidades colectivas que sostienen a los movimientos sociales (Melucci, 1994), me propongo realizar entrevistas colectivas en profundidad que sean temáticas, es decir, donde los participantes dialoguen sobre el transnacionalismo de sus prácticas y demandas; sobre las características y formas de acceso a la ciudadanía que ellos reclaman; sobre el rol que desempeña la lucha por el reconocimiento de su identidad cultural amazigh al interior del movimiento de migrantes; en fin, sobre los grandes temas que las entrevistas en profundidad me revelen como centrales para comprender al movimiento de los migrantes autoorganizados en Cataluña.

Éstas son, pues, las intuiciones iniciales que me sirven de guía para abordar, desde una perspectiva sociológica, la autoorganización de migrantes en las sociedades de instalación, un tema de estudio que, poco a poco, se hace cabida en la disciplina sociológica por las dimensiones que adquiere en el mundo (véase el ejemplo del movimiento homólogo en EEUU y Francia) y por los retos analíticos que plantea a los sociólogos de las migraciones y de los movimientos sociales.

\section{Bibliografía}

Alonso, Luis Enrique (1998). La mirada cualitativa en sociología: Una aproximación interpretativa. Madrid: Fundamentos.

CISSÉ, Madjiguène (2000). Palabra de sin papeles. Donostia: Gakoa Librak.

GARCíA CANCLINI, Néstor (2001). Culturas híbridas: Estrategias para entrar y salir de la modernidad. México: Paidós.

GRIM (GRUP de Reflexió sobre Immigració i Mèdia) (2005). Propostes per a la millora del tractament informatiu de la immigraciò. Barcelona: Fundació Jaume Bofill. En: <http://www.fbofill.org/fbofill/multimedia/debats_11.pdf>.

IÑIGUEZ, L. (2003). «Movimientos sociales: conflicto, acción colectiva y cambio social». En: VÁZQUeZ, S. Félix (coord.). Psicología del comportamiento colectivo. Barcelona: UOC.

KRUEGer, Laura (2001). «El Movimiento de los “sin papeles” en Francia en los años noventa y sus reflejos en España». Scripta Nova: Revista Electrónica de Geografía y Ciencias Sociales, 94. En: <http://www.ub.es/geocrit/sn-94-25.htm>.

Laraña, Enrique (1993). «Los movimientos sociales en España». En: Del Campo, Salustiano (ed.). Tendencias Sociales en la España de hoy. Bilbao.

- (1999). La construcción de los movimientos sociales. Madrid: Alianza Editorial.

LARAÑA, Enrique; GUSFIELD, J. (1994). Los nuevos movimientos sociales: De la ideologia a la identidad. Madrid: CIS.

LAUBENTHAL, Bárbara (2005). «La emergencia de las protestas de inmigrantes sin papeles en España: el caso de la región de Murcia». En: Pedreño C. Andrés; HERNÁNDEZ P. Manuel (coord.). La condición inmigrante: exploración e investigaciones desde la Región de Murcia. Universidad de Murcia. 
MeLUCCI A. (1994). «Asumir un compromiso: identidad y movilizaciones en los movimientos sociales». En: ReVILLA, Marisa (comp.). Movimientos sociales, acción e identidad. Zona Abierta no 69. Siglo XII. Madrid, p. 153-180.

- (2002). "¿Qué hay de nuevo en los "nuevos movimientos sociales"?. En: LaraÑa, Enrique; GUSFIELD, J. Los nuevos movimientos sociales. Madrid: CIS.

MEZZADRA, Sandro (2004). Derecho de fuga: migraciones, ciudadania y globalización. Madrid: Traficantes de Sueños.

MORERAS, Jordi (1999). Musulmanes en Barcelona. Espacios y dinámicas comunitarias. Barcelona: CIDOB.

Motril Acoge (ÁREA de Sensibilización) (2004). El encierro de "sin papeles» en la catedral de Barcelona: La lucha de los migrantes en la prensa diaria. En: $<$ http://www.motril.acoge.org/barcelona04.htm>.

SANTAMARÍA Enrique (1994). «El cerco de papel... o la construcción periodística del (anti)sujeto europeo». En: AA.VV. Extranjeros en el Paraiso. Barcelona: Virus, p. 227-241.

- (2002a). La incógnita del extraño: Una aproximación a la significación sociológica de la «inmigración no comunitaria». Rubí: Anthropos.

- (2002b). «Inmigración y barbarie. La construcción social y política del inmigrante como amenaza». Papers: Revista de Sociología, Bellaterra, no 66, p. 59-75.

STAKE, Robert E. (1998). Investigación con estudio de casos. Madrid: Ediciones Morata.

Villasante Tomas y otros (2000). La investigación social participativa. Construyendo ciudadanía. Barcelona: El Viejo Topo. 